\title{
PORRESPONDENCE
}

\section{The Diagnosis and Treatment of Penile Cancer}

by Prof. Dr. med. Oliver Walther Hakenberg, Dr. med. Desiree Louise Dräger, Prof. Dr. med. Andreas Erbersdobler, Prof. Dr. med. Carsten Maik Naumann, Prof. Dr. med. Klaus-Peter Jünemann, and Prof. Dr. med. Chris Protzel in issue 39/2018

\section{Reconstructive Possibilities}

To expand on the extremely successful article by Hakenberg et al. (1), we would like to mention the reconstructive possibilities after partial or total penectomy. Total penectomy in patients with extensive penile cancer often implies a psychological and, above all, a physical disaster for the affected patients. Even a partial penectomy can have significantly negative effects on the sex life of the patients, who sometimes completely renounce or considerably restrict sexual intercourse, in particular due to feeling shame about a shortened penis or not having a glans penis (2). Other topics that patients perceive as stressful are the reduced ability to urinate standing up (which is especially desirable) or having to use difficult and socially awkward urination aids.

From 1993 to 2018, more than 500 phalloplasties were performed at our clinic, mainly due to gender reassignment; of these, more than 300 were radial forearm flap penoids. Nine of these phalloplasties were due to reconstructive indications after extensive partial or total penectomy for penile cancer. This type of penile reconstruction allows the patient to urinate standing up without the use of urination aids and, through a subsequent prosthetic restoration, to maintain sexual intercourse.

The reported number of cases may seem small due to the low incidence of total or extensive partial penectomies. Nonetheless, we would like to point out this valuable possibility of offering phallic reconstruction to those affected, as it provides patients with a significant enhancement of quality of life. Due to its low incidence and the resulting low number of cases, however, this reconstruction should be performed in an accomplished plastic and reconstructive surgery center (3).

DOI: 10.3238/arztebl.2019.0011

\section{References}

1. Hakenberg OW, Dräger DL, Erbersdobler $A$, Naumann $C M$, Jünemann KP, Protzel C: The diagnosis and treatment of penile cancer. Dtsch Arztebl Int 2018; 115: 646-52.

2. Romero FR, Romero KRPDS, Mattos MAE de, Garcia CRC, Fernandes $R$ de C, Perez MDC: Sexual function after partial penectomy for penile cancer. Urology 2005; 66: 1292-5.

3. Sohn M, Dietrich M, Wirthmann A, Rieger UM: [Reconstructive surgery in penile cancer]. Urologe A 2018; 57: 428-34.

\section{Dr. med. Gabriel Djedovic}

Klinik für Plastische und Ästhetische, Wiederherstellungs- und Handchirurgie,

AGAPLESION Markus Krankenhaus, Frankfurt/Main

gabriel.djedovic@me.com

Prof. Dr. med. Michael Sohn

Klinik für Urologie,

AGAPLESION Markus Krankenhaus, Frankfurt/Main

Prof. Dr. Dr. med. habil. Ulrich M. Rieger

Klinik für Plastische und Ästhetische, Wiederherstellungs- und Handchirurgie,

AGAPLESION Markus Krankenhaus, Frankfurt/Main

\section{Conflict of interest statement}

The authors declare that no conflict of interest exists.

The authors of the review have chosen not to reply. 